\title{
Validation of an equine serum amyloid $A$ assay with an unusually broad working range
}

\author{
Stine Jacobsen ${ }^{1 *}$ (D), Anne Mette Vinther ${ }^{1}$, Mads Kjelgaard-Hansen ${ }^{2,3}$ and Lise Nikolic Nielsen ${ }^{3}$
}

\begin{abstract}
Background: Serum amyloid A (SAA) is a major equine acute phase protein and of great value in detection and monitoring of inflammation. A new immunoturbidometric assay based on monoclonal antibodies (VET-SAA, Eiken Chemical Co., Japan) may be useful for SAA measurements in routine diagnostic laboratories. The aim of the study was to validate the VET-SAA immunoturbidometric assay and use it to measure serum SAA concentrations in a variety of clinical cases. Precision was assessed by intra- and interassay coefficients of variation of repeated measurements of serum pools (low, intermediate, high concentrations of SAA). Accuracy was estimated by linearity under dilution. Detection limit was determined by replicate determinations of ionized water. Measurements were compared to measurements performed in a previously validated SAA assay (LZSAA assay, Eiken Chemical Co., Japan). Subsequently, the VET-SAA assay was used for measuring serum SAA concentrations in horses with and without inflammation.

Results: Detection limit was $1.2 \mathrm{mg} / \mathrm{L}$. Without modifications, the assay measured SAA concentrations with acceptable reliability in a broad concentration range $(0$ to $>6000 \mathrm{mg} / \mathrm{L}$ ). In the $0-3000 \mathrm{mg} / \mathrm{L}$ range, the assay demonstrated good precision and accuracy, and concentrations correlated well with those obtained in the LZSAA assay, albeit with a slight systematic bias. Concentrations of SAA assessed in horses with and without inflammation followed the expected pattern, with significantly higher concentrations in horses with systemic inflammation than in healthy horses and horses with non-inflammatory disease.

Conclusions: The assay was unique in its ability to measure SAA concentrations with acceptable reliability over an extreme concentration range. This is relevant in the equine species, where SAA concentrations may reach very high concentrations.
\end{abstract}

Keywords: Assay, Horse, Inflammation, Serum amyloid A, Validation

\section{Background}

Serum amyloid A (SAA) has been established as a sensitive and highly relevant marker of inflammation in horses [1-3]. SAA is a major acute phase protein in the horse, with this species seemingly unique in its ability to produce vast amounts of SAA in response to an inflammatory stimulus. Concentrations range from essentially $0 \mathrm{mg} / \mathrm{L}$ in healthy individuals to several thousand $\mathrm{mg} / \mathrm{L}$

\footnotetext{
* Correspondence: stj@sund.ku.dk

Part of the data were presented at the XVIII ${ }^{\text {th }}$ Congress of the International

Society on Animal Clinical Pathology, Tokyo, Japan, 4-8 August 2018

'Department of Veterinary Clinical Sciences, Section of Medicine and Surgery,

University of Copenhagen, Agrovej 8, Taastrup, Denmark

Full list of author information is available at the end of the article
}

in horses with severe inflammation [4]. The consistently low concentrations found in healthy horses and the extreme magnitude of response renders SAA a particularly useful marker of inflammation, as shown in a variety of clinical conditions [5-10].

Assays relevant for assessment of SAA horse-side or in the smaller laboratories of general practitioners have been validated [11, 12]. These appear reliable, but will often measure SAA in a limited concentration range, e.g. up to $3000 \mathrm{mg} / \mathrm{L}$. To be able to gauge severity/extent of inflammation, and to be able to monitor changes in inflammatory activity in severely ill horses, the ideal SAA assay must be able to measure concentrations reliably in an extremely broad range of concentrations without the

(c) The Author(s). 2019 Open Access This article is distributed under the terms of the Creative Commons Attribution 4.0 International License (http://creativecommons.org/licenses/by/4.0/), which permits unrestricted use, distribution, and 
need for multiple manual dilutions, as this increases reagent and labour costs and potentially jeopardizes the reliability of the assay. In our hospital, we have acquired extensive knowledge on the equine SAA response by measuring SAA in every horse admitted since 2007 using a previously validated immunoturbidometric assay (LZ SAA, Eiken Chemical Co., Tokyo, Japan) [13]. While this assay has proven reliable, it has two drawbacks: it is based on a combination of monoclonal and polyclonal antibodies, and it is linear in a limited concentration range. This means that 1 ) there is a higher potential for batch to batch variation due to the polyclonal antibodies $[14,15]$, and 2) samples from horses with severe inflammation need to be extensively diluted and go through repeated analysis to obtain a final SAA concentration. SAA concentrations of $3000-5000 \mathrm{mg} / \mathrm{L}$ are not uncommon, and in horses with severe and extensive inflammation (e.g. horses with peritonitis, colitis or lymphangitis), SAA concentrations may reach levels of $12.000-15.000 \mathrm{mg} / \mathrm{L}$ (unpublished data). To achieve absolute SAA concentrations, we have thus set the LZ SAA assay up with a 1:5 reflex dilution of samples containing SAA concentrations $>300 \mathrm{mg} / \mathrm{L}$ [13] and with further manual dilutions of the sample, where this reflex dilution is insufficient.

Although the LZ SAA assay has performed reliably in our setting to date, an assay based purely on monoclonal antibody would be preferable to increase specificity and inter-batch consistency. Furthermore, there is a need for an assay that measures equine SAA concentration with good reliability in the extreme concentration range encountered in horses. The purpose of the present study was thus to validate a new assay for detection of SAA in the horse, which has been developed to address these issues.

\section{Results}

\section{Assay characteristics}

Intra- and inter-assay coefficients of variation (CVs) ranged from 3.0 to $5.2 \%$ and 6.8 to $9.6 \%$, respectively (Table 1). Statistically significant deviations from a slope equal to 1 and a y-intercept equal to 0 were observed in the linear regression equation of the full concentration range of the diluted pool (Fig. 1a; Table 2), and Runs test revealed that data deviated from the linear model $(P=$ 0.0002; Table 2). When linearity under dilution was assessed in the 0 to approximately $3000 \mathrm{mg} / \mathrm{L}$ concentration range, no signs of inaccuracy were observed (Fig. 1b; Table 2).

The detection limit (DL) of the VET-SAA assay was $1.16 \mathrm{mg} / \mathrm{L}$ (blank measurements mean $0.77 \mathrm{mg} / \mathrm{L}$; standard deviation [SD] $0.13 \mathrm{mg} / \mathrm{L}$ ).

The bias percentages were within the predefined acceptance criterion for both interfering substances (Additional file 1).
Table 1 Intra- and inter-assay variation in determination of serum amyloid (SAA) concentrations in equine serum samples

\begin{tabular}{lllll}
\hline Comparison & $\begin{array}{l}\text { No. of } \\
\text { repeats }\end{array}$ & \multicolumn{2}{l}{ SAA concentration $(\mathrm{mg} / \mathrm{L})$} & $\begin{array}{l}\text { Coefficient } \\
\text { of variation } \\
(\%)\end{array}$ \\
\cline { 6 - 6 } $\begin{array}{l}\text { Intra-assay } \\
\text { Low conc. }\end{array}$ & 10 & 124.7 & 3.8 & 3.0 \\
Intermediate conc. & 10 & 805.3 & 41.9 & 5.2 \\
High conc. & 10 & 4443 & 161.3 & 3.6 \\
& & & & \\
Low conc. & 10 & 113.4 & 7.7 & 6.8 \\
Intermediate conc. & 10 & 842.0 & 63.6 & 7.6 \\
High conc. & 10 & 4646 & 445.7 & 9.6 \\
\hline
\end{tabular}

\section{Method comparisons and overlap performance}

When the two assays were compared in the 0 to approximately $3000 \mathrm{mg} / \mathrm{L}$ concentration range, a high degree of correlation was observed between them (Fig. 2b;). The Deming regression of method comparison revealed a small proportional disagreement (slope [95\% confidence interval] was $1.08[1.04,1.12])$, but no systematic inaccuracy (Y-intercept [95\% confidence interval] was $39.6[-7.6$, 86.8]). The proportional disagreement was confirmed by direct plot of SAA measurements obtained by the two assays (Fig. 2b), visualizing the tendency of the LZSAA to result in slightly (8\%) higher concentrations of SAA than the VET-SAA. When the two assays were compared in the full concentration range ( 0 to $9274 \mathrm{mg} / \mathrm{L})$, there was large proportional and systematic bias (Fig. 3), caused by concentrations assessed in the LZSAA assay trailing off at concentrations higher than $3000 \mathrm{mg} / \mathrm{L}$ (Fig. 2a).

Overlap assessment revealed the expected differences between healthy horses and horses with non-inflammatory and inflammatory disease. Median concentration in the three groups were 4.3, 6.1, and $4461 \mathrm{mg} / \mathrm{L}$ (Fig. 4). Concentrations of SAA in the three groups differed significantly $(P<0.0001)$, with levels in horses with inflammation being significantly higher than in healthy horses and horses with non-inflammatory disease $(P<0.0001)$, while concentration in healthy horses and horses with non-inflammatory disease did not differ significantly $(P=0.8)$. Overview of diagnoses/ reason for hospitalization in the three groups of horses can be found in Additional file 2.

\section{Reference interval}

The reference interval (RI) was determined in a diverse group of healthy horses. Age ranged from 1 day to 20 years (mean $=4.9$ years), 22 breeds were represented. There were 30 geldings, 37 mares, and 36 stallions; gender was unknown in one horse (Additional file 3). The RI was determined (using the upper limit of the 90\% confidence interval) to be up to $23.6 \mathrm{mg} / \mathrm{L}$ (Table 3) 

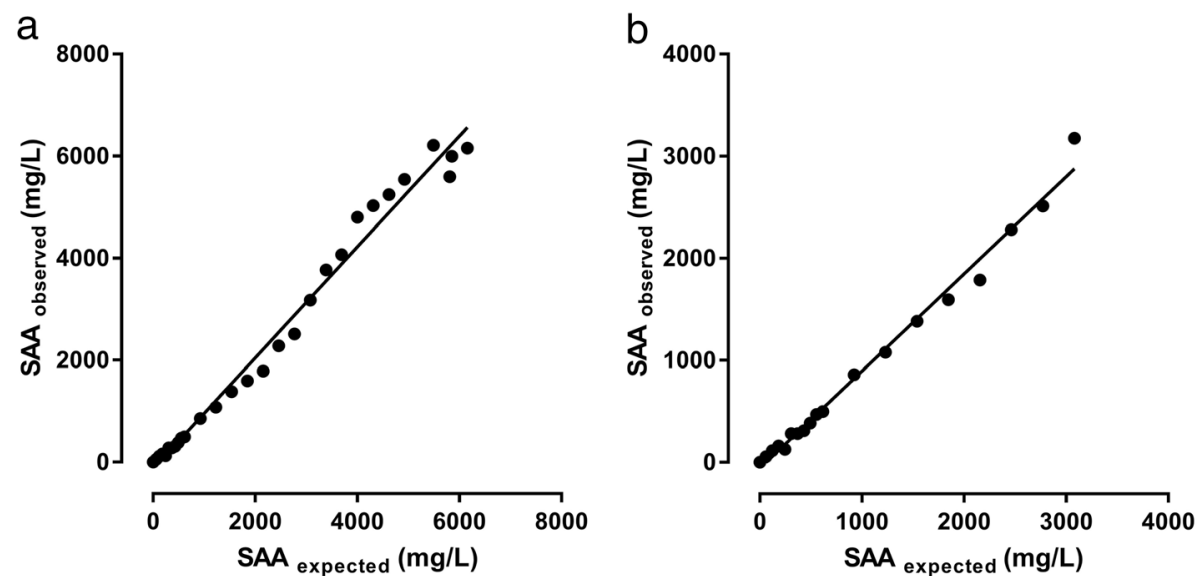

Fig. 1 Linearity under dilution of an equine serum pool with high concentration of serum amyloid A (SAA). Determinations were performed by means of an immunotubidometric assay developed for determination of SAA concentrations in horses (VET-SAA). Panel a shows linearity under dilution in the full concentrations range, panel $\mathbf{b}$ shows linearity under dilution in the most frequently encountered/relevant concentration range $(0-3000 \mathrm{mg} / \mathrm{L})$. While the assay showed slight signs of inaccuracy in the full concentration range (a, Table 2), no significant deviation from a slope equal to 1 and a $y$-intercept equal to 0 were observed in the linear regression equation ( $x=$ the expected level according to dilution, $y=$ the observed concentration) in the 0 to approximately $3000 \mathrm{mg} / \mathrm{L}$ concentration range (b, Table 2)

with 96/104 (92.3\%) horses having SAA concentrations $<5 \mathrm{mg} / \mathrm{L}$.

\section{Analyses of clinical and experimentally induced inflammation}

Concentrations of SAA differed significantly between groups of horses with different inflammatory status $(P<$ $0.0001)$. In healthy horses, average (range) SAA concentration was $2.0(0-23.6) \mathrm{mg} / \mathrm{L}$, in horses with noninflammatory diseases it was $45.1(0.2-1036) \mathrm{mg} / \mathrm{L}$ and in horses with local and systemic inflammation average (range) SAA concentrations were 238.7 (0.7-1517) and 2494 (4.3-9275) mg/L, respectively (Fig. 5). Concentrations of SAA were significantly higher in horses with systemic inflammation than in the other groups $(P<0.0001)$, while concentrations in the other three groups of horses did not differ.

SAA concentrations increased significantly in horses with inflammation induced by castration $(P=0.0006)$ or experimental IV injection of lipopolysaccharide (LPS) $(P<0.0001)$ (Fig. 6). After castration, SAA levels were higher than pre-surgical levels on day $1(P=0.0005), 2$ $(P=0.006)$, and $3(P=0.03)$; on day 8 concentrations had returned to pre-surgical levels. After systemic inflammation induced by IV injection of LPS, SAA concentrations were increased relative to pre-injection levels from 4 to $96 \mathrm{~h}$.

\section{Discussion}

The VET-SAA assay performed reliably. Repeatability was good, and acceptable accuracy (linearity under dilution) was observed in a very broad concentration range. In the most frequently encountered/relevant concentration range $(0-3000 \mathrm{mg} / \mathrm{L})$ the assay showed no signs of inaccuracy. When the entire concentration range $(0-$ $6159.7 \mathrm{mg} / \mathrm{L}$ ) was analysed, slight signs of inaccuracy were detected (Table 2) consisting of a slight overestimation in the range of 3000-6000 mg/mL (Fig. 1). Considering the response pattern of SAA with fast and pronounced concentration increase in response to an inflammatory stimulus and a short half-life with resulting quick concentration decline after effective treatment [3],

Table 2 Analytical inaccuracy of serum amyloid A (SAA) concentrations assessed by dilution of an equine serum pool

\begin{tabular}{lll}
\hline Full concentrations range (up to $6159.7 \mathrm{mg} / \mathrm{L})$ & -intercept (95\% confidence interval) & $-130(-293.3,33.19)$ \\
& Slope (95\% confidence interval) & $1.087(1.035,1.140)$ \\
& $\mathrm{P}$ (Runs test) & 0.0002 \\
Concentration range up to $3000 \mathrm{mg} / \mathrm{L}$ & $\mathrm{r}^{2}$ & 0.99 \\
& y-intercept (95\% confidence interval) & $-58.5(-129.6,12.59)$ \\
& Slope (95\% confidence interval) & $0.952(0.902,1.003)$ \\
& $\mathrm{P}$ (Runs test) & 0.4 \\
\hline
\end{tabular}



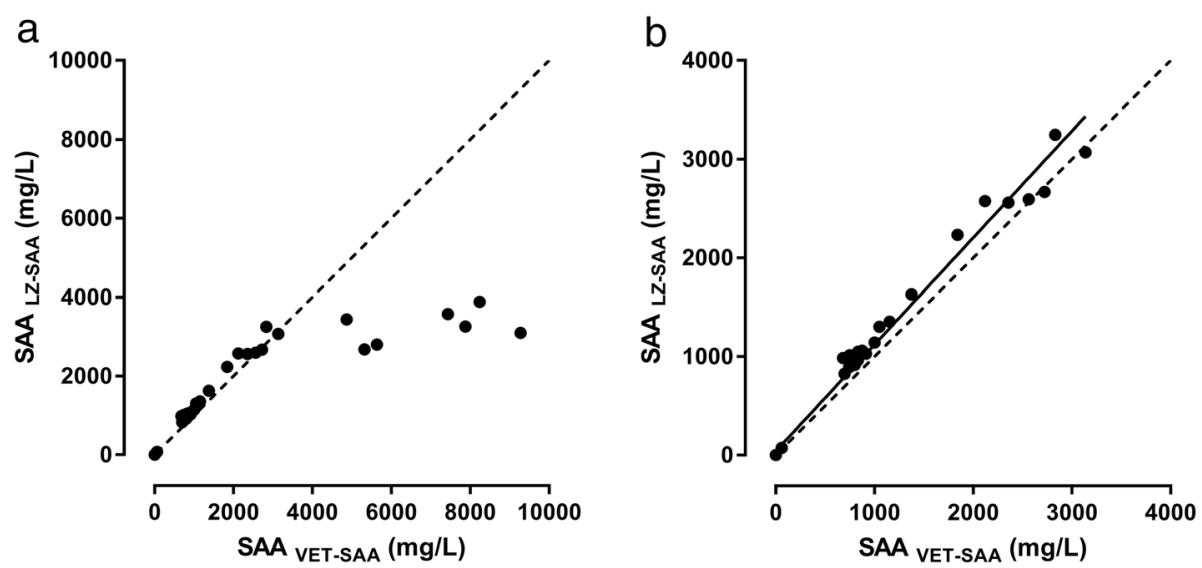

Fig. 2 Comparison of serum amyloid A (SAA) concentrations measured in a novel immunotubidometric assay developed for determination of SAA concentrations in horses (VET-SAA) and in an immunotubidometric assay previously validated for use in horses (LZ SAA). Panel (a) shows method comparison in the full concentration range, panel (b) shows method comparison in the most frequently encountered/relevant concentration range $(0-3000 \mathrm{mg} / \mathrm{L})$, solid line in $(\mathbf{b})=$ Deming regression line, dashed lines = perfect agreement $(X=Y)$. Concentrations assessed in the LZ SAA assay trailed off at around $3000 \mathrm{mg} / \mathrm{L}$ causing poor correlation between the two assays at higher concentrations (a), but in the 0 to approximately $3000 \mathrm{mg} / \mathrm{L}$ concentration range, a high degree of correlation was observed between the two assays (b)

the observed minor inaccuracy is considered clinically insignificant, as the inaccuracy at no point prevents detection of increases or declines in SAA concentrations (Fig. 1).

Concentrations measured in the VET-SAA assay were significantly correlated with concentrations in the previously validated LZ SAA assay in the $0-3000 \mathrm{mg} / \mathrm{L}$ range. Beyond this range of concentrations, a proportional and

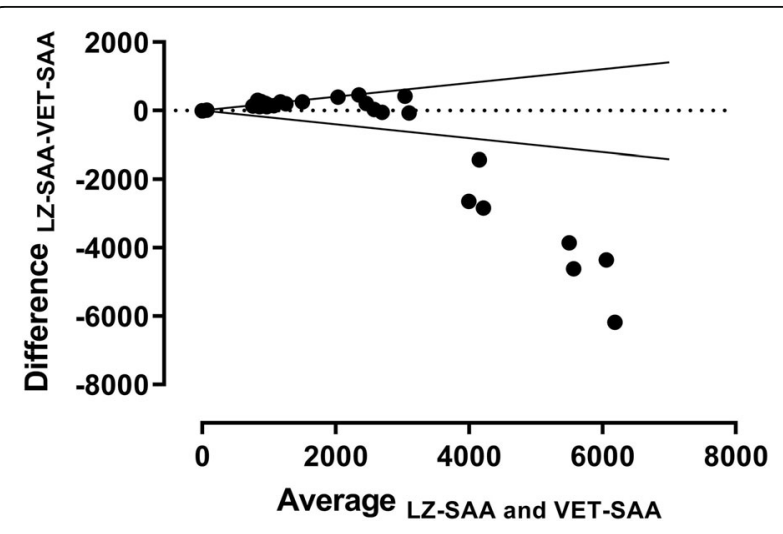

Fig. 3 Bland-Altman plot of serum amyloid A (SAA) concentrations measured in a novel immunotubidometric assay developed for determination of SAA concentrations in horses (VET-SAA) and in an immunotubidometric assay previously validated for use in horses ( $L Z$ SAA). The difference between concentration readout in the two assays (y-axis) is plotted against the average SAA concentration ( $x$-axis). The plot shows a large proportional and systematic bias, where the negative difference between concentrations measured in the two assays increases with increasing SAA concentration. The bias clearly exceeds the limits of the inherent combined imprecision of the assays (full lines), when concentrations exceeds $4000 \mathrm{mg} / \mathrm{L}$ (Data on LZ SAA imprecision derived from [13]; limits calculated as described in [16])

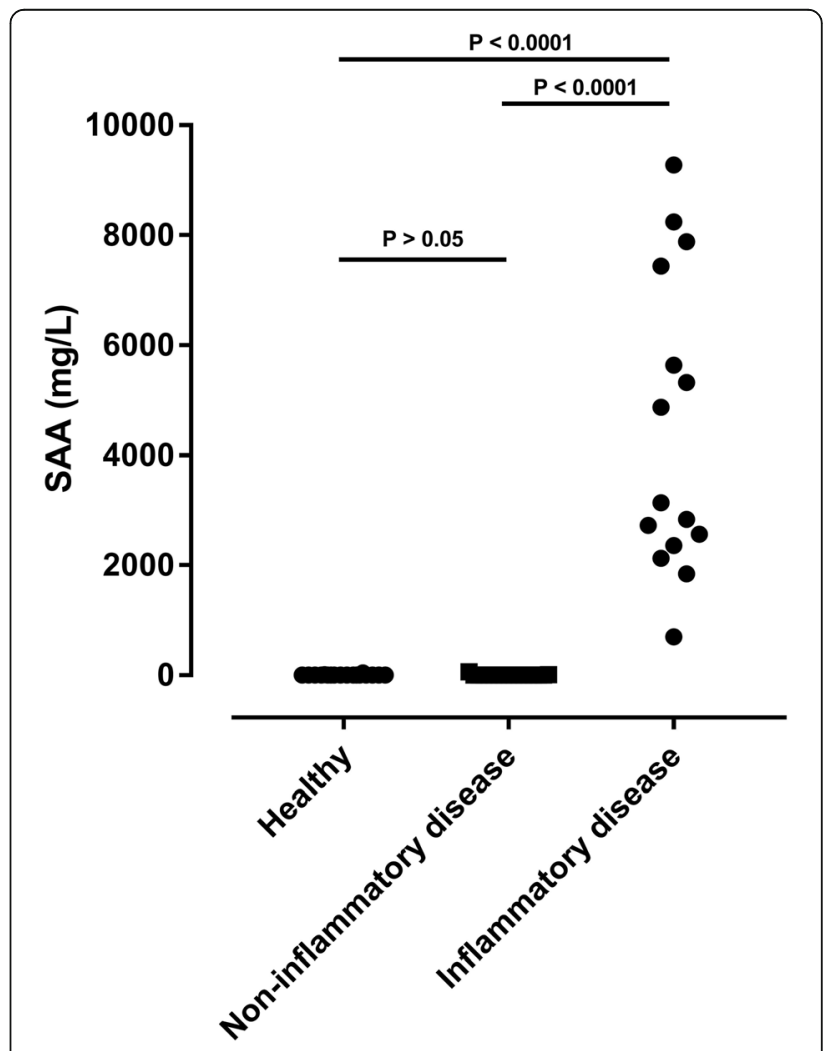

Fig. 4 Serum concentrations of serum amyloid A (SAA) determined in different groups of horses by means of an immunotubidometric assay developed for determination of SAA concentrations in horses (VET-SAA) 
Table 3 Reference interval (and confidence intervals) determined in the VET-SAA assay

\begin{tabular}{llllll}
\hline$n$ & Median $(\mathrm{mg} / \mathrm{L})$ & Range $(\mathrm{mg} / \mathrm{L})$ & Reference interval $(\mathrm{RI})(\mathrm{mg} / \mathrm{L})$ & $\begin{array}{l}90 \% \text { confidence interval of } \\
\text { lower limit of Rl }(\mathrm{mg} / \mathrm{L})\end{array}$ & $\begin{array}{l}90 \% \text { confidence interval of } \\
\text { upper limit of RI (mg/L) }\end{array}$ \\
\hline 104 & 1.3 & $<1.2-23.6$ & $<1.2-12.5$ & $<1.2$ & $7.0-23.6$
\end{tabular}

systematic bias between the two assays was detected (Figs. 2 and 3); this was caused by the quantitative inability of the LZ SAA assay at higher concentrations. In the $0-3000 \mathrm{mg} / \mathrm{L}$ concentration range, SAA concentrations measured in the VET-SAA assay were significantly lower than in the LZ SAA assay; this proportional difference was, however, small (8\%), which ensures a considerable agreement on clinical classification between the two assays and has the added benefit that clinicians will not have to get acquainted with another concentration range. Due to the heterologous calibration of the assay, the true concentration of equine SAA is unknown. No standard preparations of purified equine SAA are available, possibly due to the well-known difficulties in purifying SAA [17]. Consequently, in the VET-SAA, LZ SAA and other SAA assays used in equine medicine, calibration curves are based on recombinant human SAA, and concentrations are thus expressed as human equivalents. Between-assay variations in affinity of the antibodies towards the different isoforms [18] of the equine SAA protein may result in different concentration read-outs, as a higher affinity will translate into a higher SAA concentration read from the calibration

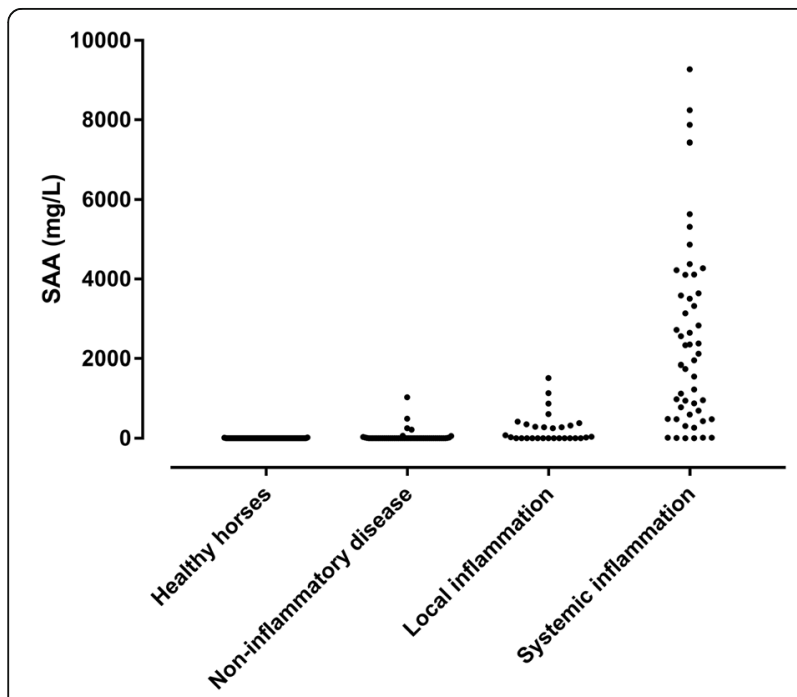

Fig. 5 Serum concentrations of serum amyloid A (SAA) determined in healthy horses and horses with different inflammatory disease by means of an immunotubidometric assay developed for determination of SAA concentrations in horses (VET-SAA). Concentrations of SAA were significantly higher in horses with systemic inflammation than in the other three groups $(P<0.0001)$, while concentrations in healthy horses, horses with noninflammatory diseases and horses suffering from local inflammation did not differ statistically significantly $(P>0.05)$ curve. This may be the explanation for the two assays (both of which perform heterologous SAA assessment) yielding slightly different concentrations. Such slight difference in reactivity towards equine SAA and the human recombinant SAA calibrator could likely also be the source of the slight deviation from linearity under dilution described above, as this could result in lack of parallelism between the signals generated by the diluted sample and the calibration curve (a prerequisite for perfect linearity) .

There was no prozone effect in the assay. Prozone effect (also called hook effect) may occur when there is an excess of analyte and all antibodies in the assay are completely saturated. This is a highly undesirable feature, as it results in falsely low concentration outputs that goes unnoticed unless samples are analysed in several dilutions. Particularly when working with equine SAA, where markedly high concentrations are observed frequently $[10,19,20]$, it is of great importance to ascertain that the assay does not have prozone issues. Within the concentration range of 0 to more than $6000 \mathrm{mg} / \mathrm{L} \mathrm{SAA}$ the VET-SAA assay did not show prozone effect, similar to a previously validated multi-species SAA assay from the Eiken Chemical Co. [4]. The VET-SAA assay was able to measure SAA concentrations up to more than $9000 \mathrm{mg} / \mathrm{L}$ (Fig. 4). In the fairly rare occasions where SAA concentrations exceed $6000 \mathrm{mg} / \mathrm{L}$, users should be aware that accuracy is unknown and further dilution of the sample may be advisable. To have a working range of 0 to $6000 \mathrm{mg} / \mathrm{L}$ SAA is exceptional for a clinically relevant, random-access assay and renders the assay particularly well suited for use in equine medicine.

SAA concentrations determined in the VET-SAA assay were not affected by haemolysis or lipaemia. Concentrations of the interfering molecules were similar to those used in a previous study, which showed no effect of these on SAA assessed in a commercially available ELISA [21]. Concentrations of haemoglobin and lipid were chosen to represent those observed in diseased horses, and SAA concentrations can thus be measured correctly in samples from horses with haemolytic disease or lipaemia.

As described in our review on assay validation [2], the purpose of assessing overlap performance (phase II of test validation) is to detect differences in analyte concentrations between healthy and clearly diseased individuals. This should be seen as a resource-sparing prelude to the resource-demanding phase III, in which clinical performance of the assay is evaluated. Our results were as 

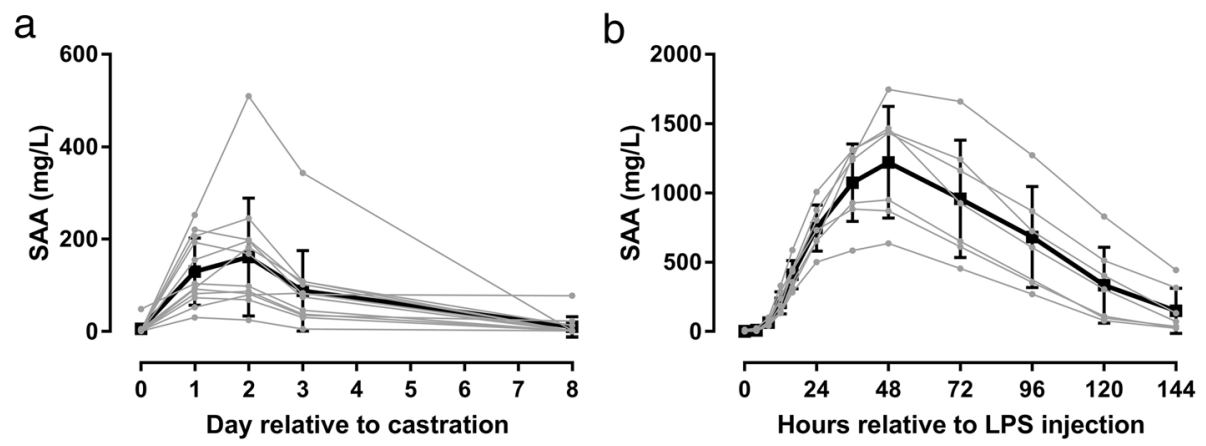

Fig. 6 Serum concentrations of serum amyloid A (SAA) determined in horses undergoing castration and experimental systemic inflammation. Individual (grey lines) and average (black lines, error bars show standard deviations) serum amyloid A (SAA) concentrations in 12 horses before and 1, 2, 3 and 8 days after castration (a) and in 7 horses before and 4, 8, 12, 16, 24, 36, 48, 72, 96, 120 and $144 \mathrm{~h}$ after IV injection of lipopolysaccharide (LPS) (b). Serum concentrations of SAA were determined by means of an immunotubidometric assay developed for determination of SAA concentrations in horses (VET-SAA)

expected: horses with moderate-severe inflammatory disease had significantly higher blood SAA concentrations than healthy horses and horses with non-inflammatory disease (Fig. 4). We expanded the simple phase II overlap assessment and showed that in horses with local inflammation SAA concentrations were not significantly different from those found in healthy horses and horses with non-inflammatory disease (Fig. 5). It has been noted in previous studies that local inflammation might not give rise to increased blood concentrations of SAA, potentially because of the walled-off nature of diseases such as Rhodococcus pneumonia or abscesses $[8,22]$.

The temporal concentration changes observed after a surgical trauma (castration) and experimental induction of systemic inflammation by IV injection of LPS (Fig. 6) were as expected and as shown in previous studies [23, 24]. These results demonstrate that the assay is fully capable of monitoring expected changes in SAA levels throughout relevant clinical phases of inflammation.

The upper limit of the $90 \%$ confidence interval of the RI was $23.9 \mathrm{mg} / \mathrm{L}$, which would constitute the diagnostic cut-off when based solely on the data on healthy horses. Using this cut-off, the diagnostic specificity would by definition be $97.5 \%$; it should, however, always be considered whether the distribution of pathological levels of the analyte may allow establishment of a clinical decision level that would increase the diagnostic sensitivity without compromising diagnostic sensitivity. If so, the clinical applicability of the test would be enhanced (by increasing the positive predictive value and thus ability to 'rule-in' presence of pathology) [25]. This is the case for SAA, as the diagnostic sensitivity of major acute phase proteins is provided by the large relative change in concentration in response to inflammation, not by adopting a cut-off level close to the RI with the purpose of identifying individuals with the slightest increases in serum SAA. Using a cut-off limit somewhat above the normal range can enhance the diagnostic specificity of equine SAA without seriously impairing diagnostic sensitivity [26], as most horses suffering from an inflammatory condition will have serum SAA levels that are greatly elevated above the upper limit of the RI. Thus, we propose that using a clinical decision level is more relevant than using the RI for differentiating healthy and diseased horses. Using the LZ SAA assay such a clinical decision limit of $30 \mathrm{mg} / \mathrm{L}$ was established at the Large Animal Teaching Hospital, University of Copenhagen, Denmark and has been used for more than 10 years. Considering the fact that the VET-SAA assay measures concentrations essentially similar to the LZ SAA assay, our current decision level of $30 \mathrm{mg} / \mathrm{L}$ may prove to remain relevant.

In conclusion, the VET-SAA assay measured SAA in equine serum with analytical performance acceptable for clinical purposes. It was able to detect the expected differences in SAA concentrations between healthy horses and horses with different inflammatory and non-inflammatory diseases as well as concentration changes occurring over time after induction of inflammation. With its reliability in an exceptional concentration range, it is particularly wellsuited for the equine species, where SAA concentrations range from essentially $0 \mathrm{mg} / \mathrm{L}$ in healthy individuals to > $5.000-10.000 \mathrm{mg} / \mathrm{L}$ in horses suffering from severe systemic inflammation. The assay is automated, rapid, and applicable for random-access analysers, which facilitates use in routine diagnostic laboratories. Furthermore, since the VET-SAA is based on monoclonal antibodies, it may be associated with a strong long-term and inter-batch performance [14].

\section{Conclusions}

The new immunoturbidometric assay (VET-SAA, Eiken Chemical Co., Japan) is unique in its ability to measure SAA concentrations with acceptable reliability over an 
extreme concentration range (up to $>6000 \mathrm{mg} / \mathrm{L}$ ). This is relevant in the equine species, where SAA concentrations may reach very high concentrations. The detection limit is $1.16 \mathrm{mg} / \mathrm{L}$, and the RI was determined to be up to $23.6 \mathrm{mg} / \mathrm{L}$. The assay was able to differentiate horses with different inflammatory status and to monitor changes in inflammatory activity. Its characteristics (automated, rapid, based on monoclonal antibodies) confers a high applicability.

\section{Methods}

\section{Serum amyloid $A$ analyses}

The VET-SAA assay (Eiken Chemical Co. Tokyo, Japan) is an immunoturbidometric assay using monoclonal rat anti-human SAA1 antibody. Analyses were performed using an automated analyser (Advia 1800, Siemens Healthineers, Ballerup, Denmark) according to the manufacturer's instructions. These instructions entail a 1:4 pre-analysis dilution of each sample and, when SAA concentration in the sample exceeds $200 \mathrm{mg} / \mathrm{L}$, a further 1:14 reflex dilution is performed as an integral part of the assay conditions on the automated analyser. The calibration curve was made using the calibrator (human recombinant SAA) supplied with the kit.

For method comparison, samples were analysed using the previously validated immunoturbidometric LZ SAA assay (Eiken Chemical Co. Tokyo, Japan), which is based on polyclonal rabbit anti-human SAA antibody and monoclonal rat anti-human SAA1 antibody and uses human recombinant SAA as a calibrator [13]. This assay was used according to the manufacturer's instruction (which entails a 1:4 pre-analysis dilution of samples) with the exception that all samples containing SAA concentrations $>300 \mathrm{mg} / \mathrm{L}$ underwent a reflex dilution of 1 : 5 and were re-analysed automatically, as previous studies had demonstrated the need for sample dilution to expand the working range of the assay $[12,13]$. No manual sample dilution was performed.

\section{Assay characteristics}

Precision was assessed by intra- (same day) and interassay (non-consecutive days) CV from the mean and SD of 10 replicate determinations of three serum pools containing low, intermediate and high concentrations of SAA (Table 1). Pools were obtained by mixing serum from at least 5 different horses. To avoid effect of repeated thawing and freezing, pools used for the determination of inter-assay variation were aliquotted and stored at $-80^{\circ} \mathrm{C}$ until use. Only aliquots needed for each analytical run were thawed. Inaccuracy was investigated by evaluating linearity under dilution. This was performed as serial dilutions of a serum pool containing a very high concentration of SAA $(6159.7 \mathrm{mg} / \mathrm{L})$, which was diluted to obtain sample volume percentages of 0,1 ,
$2,3,4,5,6,7,8,9,10,15,20,25,30,35,40,45,50,55$, $60,65,70,75,80,85,90,95$ and $100 \%$.

The DL was determined by 20 replicate determinations of ionized water.

Interference of haemolysis and lipaemia was tested. A haemolytic solution was produced by the osmotic shock procedure described by the CLSI guidelines (Guideline EP07, https://clsi.org/standards/products/method-evaluation/documents/ep07/). In brief, EDTA-stabilized equine blood was centrifuged, plasma was discarded and the cell pellet was washed three times using $0.9 \% \mathrm{NaCl}$. Erythrocytes were lysed by adding distilled water and freezing the sample overnight. After thawing and a single washing procedure to remove cellular debris, a solution containing approximately $100 \mathrm{~g} / \mathrm{L}$ haemoglobin was obtained. A commercial fat emulsion solution (Intralipid 20\% emulsion, Sigma Aldrich, VWR International, Søborg, Denmark) was acquired. The haemoglobin and lipid solutions were added to two pools of equine serum containing approximately $110 \mathrm{mg} / \mathrm{L}$ and $560 \mathrm{mg} / \mathrm{L}$ SAA in different concentrations (total concentration of haemoglobin $=0.625 \mathrm{~g} / \mathrm{L}, 2.5 \mathrm{~g} / \mathrm{L}$ or $10 \mathrm{~g} / \mathrm{L}$; total concentrations of lipids $=0.31 \mathrm{~g} / \mathrm{L}, 1.25 \mathrm{~g} / \mathrm{L}$ or $5 \mathrm{~g} / \mathrm{L}$ ) and SAA concentrations assessed by the VET-SAA assay 3 times (Additional file 1). Acceptance criterion was set at $-1+10 \%$.

\section{Animals and samples}

To assess overlap performance of the assay for detection of systemic inflammation, samples from healthy horses $(n=18)$, horses suffering from non-inflammatory disease $(n=17)$ and horses suffering from diseases characterized by moderate to severe systemic inflammation $(n=15)$ were included. To compare SAA levels in horses with different inflammatory states, an additional 86 healthy horses, 51 horses with non-inflammatory disease and 50 horses with systemic inflammatory disease of varying severity were included along with 29 horses suffering from localized inflammation. The patient samples originated from equine patients presented at the Large Animal Teaching Hospital at University of Copenhagen, Denmark. All patients underwent clinical examination, routine haematology and serum biochemistry and additional diagnostic procedures such as diagnostic imaging, synoviocentesis, endoscopic procedures, and/or diagnostic analgesia to achieve a final diagnosis. Horses with non-inflammatory disease were diagnosed with non-strangulating intestinal conditions $(n=14$; small and large intestinal obstipations, nephro-splenic large colon entrapment, right dorsal displacement of the large colon), musculoskeletal conditions ( $n=15$; navicular disease, flexural deformity, osteoarthrosis, upward fixation of the patella, radial nerve paralysis, kissing spines, unrideability), cardiac conditions $(n=6$; mitral or aortic valve insufficiency), dental disease $(n=3$; equine odontoclastic tooth resorption and hypercementosis), upper 
airway diseases $(n=2$; laryngeal hemiplegia, pharyngeal collapse), metabolic diseases $(n=5$; hyperlipidemia, pituitary pars intermedia dysfunction), and miscellaneous conditions $(n=6$; umbilical hernia, behavioural issues, retinal detachment, blocked tear canals). Horses with systemic inflammation were diagnosed with orthopedic infections $(n=16$; lymphangitis/cellulitis, wound infections, septic synovitis, hoof abscess), gastrointestinal and intraabdominal infections $(n=18$; colitis, enteritis, peritonitis), airway infections $(n=5$; pneumonia, pleuropneumonia), pyrexia $(n=5)$, and miscellaneous conditions $(n=6$; bladder rupture, septicemia, neoplasia, retained placenta, thymitis, neuritis). Horses with localized inflammation were diagnosed with abscesses/ fistulas $(n=12)$, strangles/lymphadenopathy $(n=4)$, rectal tears $(n=3)$, septic funiculitis/scirrhous cord $(n=4)$, phlebitis $(n=1)$, sinusitis $(n=3)$, and guttural pouch infections $(n=2)$.

The resulting 104 $(18+86)$ samples from healthy horses were used for determining a population-based RI of SAA.

Two sets of sequential serum samples were available from two previous studies involving 12 horses undergoing castration (unpublished data) and 7 horses subjected to IV injection of LPS resulting in systemic inflammation [23]. In horses undergoing castration, samples were obtained before and 1,2, 3 and 8 days after the surgical procedure. The castrated horses were clinically healthy before surgery and had a normal postoperative recovery. In horses with experimental LPS-induced inflammation, samples were obtained at $0,4,8,12,16,24,36,48,72$, 96,120 and $144 \mathrm{~h}$ relative to the injection.

\section{Statistical analyses}

Arithmetic means, standard deviations, medians, intraand inter-assay CVs were estimated using routine descriptive statistical procedures. The DL $(P<0.01)$ was estimated as the mean $+3 \mathrm{SD}$ of SAA determination of blank samples. Linearity under dilution was investigated by linear regression analysis. Runs test was performed to determine whether data deviated significantly from the applied model. The effect of different concentrations of haemoglobin or lipid on measured SAA concentrations were examined by calculating the bias percentage as described by Kjelgaard-Hansen and Jensen [27] (Additional file 1). Method comparison of the two assays was performed by Deming regression analysis and visualized in Bland-Altman plots. Calculation of RI and 90\% confidence interval was performed with a dedicated software (Reference Value Advisor, http://www.biostat.envt.fr/referencevalue-advisor/) using nonparametric methods due to the skewed distribution of native data (determined by the D'Agostino-Pearson omnibus test) as described by Geffre et al. [28]. Overlap performance was assessed by comparing groups (healthy, non-inflammatory disease, inflammatory disease) using the Kruskal-Wallis test; when significant results were obtained, Dunn's multiple comparison test was performed. Differences between groups with different inflammatory status (healthy, non-inflammatory, local inflammation, systemic inflammation) were analysed with one-way ANOVA and the post hoc test Tukey's multiple comparisons test. Changes in SAA levels in castrated horses and horses with LPS-induced inflammation were evaluated using the repeated measures ANOVA and Tukey's multiple comparisons post hoc test. A level of significance of 0.05 was used unless otherwise stated. Statistics were performed using a commercial package (Graph PadPrism 8.00 for windows, GraphPad Software, La Jolla, California, USA).

\section{Supplementary information}

Supplementary information accompanies this paper at https://doi.org/10. 1186/s12917-019-2211-3.

Additional file 1. Interference testing, methods and results.

Additional file 2. Overview of diagnoses/reason for hospitalization in the three groups of horses used to assess overlap performance.

Additional file 3. Overview of healthy horses used for calculating reference interval.

\section{Acknowledgements}

The authors would like to acknowledge laboratory technicians Claus Stjernegaard, Tina Roust and Massimo Girotto for value assistance with sample handling and analysis. Veterinarian Danuta Hedlund is thanked for assistance with sampling from horses undergoing castration.

\section{Authors' contributions}

SJ conceived the study and designed it, was responsible for data integrity, analysis and interpretation, and prepared the manuscript. AMV collected data. MKH was responsible for data analysis and interpretation. LNN contributed to study design and was responsible for data collection and study execution. All authors have read and approved the final manuscript. SJ had full access to all the data in the study and takes responsibility for the integrity of the data and the accuracy of the data analysis.

\section{Funding}

The study was funded by Eiken Chemical Co, Tokyo, Japan. The authors have no financial conflict of interest to declare.

\section{Availability for data and materials}

The datasets used and/or analysed during the current study are available from the corresponding author on reasonable request.

\section{Ethics approval and consent to participate}

All blood samples from client-owned horses originated from the biobank of the Large Animal Teaching Hospital of University of Copenhagen with permission from the local ethical committee. Samples from horses undergoing experimental induction of systemic inflammation were obtained from a previous study, where the experimental protocol had been preapproved by the ethical committee of the Large Animal Teaching Hospital of University of Copenhagen and by the Danish Animal Experiments Inspectorate (permit 2011/561-1996). The animal experiment was carried out according to the Danish Animal Testing Act and EU Directive 2010/63/EU for animal experiments. 


\section{Competing interests}

The authors declare that they have no competing interests.

\section{Author details}

'Department of Veterinary Clinical Sciences, Section of Medicine and Surgery, University of Copenhagen, Agrovej 8, Taastrup, Denmark. ${ }^{2}$ Ascendis Pharma A/S, Tuborg Boulevard 12, Hellerup, Denmark. ${ }^{3}$ Department of Veterinary Clinical Sciences, The Veterinary Diagnostic Laboratory, University of Copenhagen, Dyrlaegevej 46, Frederiksberg C, Denmark.

Received: 31 July 2019 Accepted: 9 December 2019

Published online: 19 December 2019

\section{References}

1. Jacobsen $\mathrm{S}$, Andersen $\mathrm{PH}$. The acute phase protein serum amyloid A (SAA) as a marker of inflammation in horses. Eq Vet Edu. 2007;19:38-46.

2. Kjelgaard-Hansen M, Jacobsen S. Assay validation and diagnostic applications of major acute-phase protein testing in companion animals. Clin Lab Med. 2011;31:51-70.

3. Witkowska-Pilaszewicz OD, Zmigrodzka M, Winnicka A, Miskiewicz A, Strzelec K, Cywinska A. Serum amyloid A in equine health and disease. Equine Vet J. 2019:51:293-8.

4. Christensen M, Jacobsen S, Ichiyanagi T, Kjelgaard-Hansen M. Evaluation of an automated assay based on monoclonal anti-human serum amyloid $\mathrm{A}$ (SAA) antibodies for measurement of canine, feline, and equine SAA. Vet J. 2012:194:332-7.

5. Andersen SA, Petersen HH, Ersboll AK, Falk-Ronne J, Jacobsen S. Vaccination elicits a prominent acute phase response in horses. Vet J. 2012;191:199-202.

6. Andreassen SM, Vinther AML, Nielsen SS, Andersen PH, Tnibar A, Kristensen AT, Jacobsen S. Changes in concentrations of haemostatic and inflammatory biomarkers in synovial fluid after intra-articular injection of lipopolysaccharide in horses. BMC Vet Res. 2017;13:182

7. Busk $\mathrm{P}$, Jacobsen $\mathrm{S}$, Martinussen T. Administration of perioperative penicillin reduces postoperative serum amyloid $A$ response in horses being castrated standing. Vet Surg. 2010;39:638-43.

8. Cohen ND, Chaffin MK, Vandenplas ML, Edwards RF, Nevill M, Moore JN, Martens RJ. Study of serum amyloid A concentrations as a means of achieving early diagnosis of Rhodococcus equi pneumonia. Eq Vet J. 2005;37: 212-6.

9. Pollock PJ, Prendergast M, Schumacher J, Bellenger CR. Effects of surgery on the acute phase response in clinically normal and diseased horses. Vet Rec. 2005;156:538-42

10. Viner M, Mazan M, Bedenice D, Mapes S, Pusterla N. Comparison of serum amyloid $A$ in horses with infectious and noninfectious respiratory diseases. J Eq Vet Sci. 2017;49:11-3.

11. Jacobsen S, Kjelgaard-Hansen M. Evaluation of a commercially available apparatus for measuring the acute phase protein serum amyloid $A$ in horses. Vet Rec. 2008;163:327-30.

12. Schwartz D, Pusterla N, Jacobsen S, Christopher MM. Analytical validation of a new point-of-care assay for serum amyloid $\mathrm{A}$ in horses. Equine Vet J. 2018 ; 50:678-83.

13. Jacobsen S, Kjelgaard-Hansen M, Hagbard Petersen H, Jensen AL. Evaluation of a commercially available human serum amyloid A (SAA) turbidometric immunoassay for determination of equine SAA concentrations. Vet J. 2006; 172:315-9.

14. Kjelgaard-Hansen M. Comments on measurement of C-reactive protein in dogs. Vet Clin Pathol. 2010;39:402-3.

15. Cerón JJ, Ohno K, Caldin M. A seven-point plan for acute-pahse protein interpretation in companion animals. Vet J. 2008:177:6-7.

16. Jensen AL, Kjelgaard-Hansen M. Method comparison in the clinical laboratory. Vet Clin Pathol. 2006;35:276-86.

17. Christensen MB, Sorensen JC, Jacobsen S, Kjelgaard-Hansen M. Investigation of the solubility and the potentials for purification of serum amyloid A (SAA) from equine acute phase serum--a pilot study. BMC Res Notes. 2013:6:152.

18. Jacobsen S, Niewold TA, Halling-Thomsen M, Nanni S, Olsen E, Lindegaard C, Andersen PH. Serum amyloid A isoforms in serum and synovial fluid in horses with lipopolysaccharide-induced arthritis. Vet Immunol Immunopathol. 2006:110:325-30.

19. Haltmayer E, Schwendenwein I, Licka TF. Course of serum amyloid A (SAA) plasma concentrations in horses undergoing surgery for injuries penetrating synovial structures, an observational clinical study. BMC Vet Res. 2017;13:137.
20. Pihl TH, Nielsen MK, Olsen SN, Leifsson PS, Jacobsen S. Nonstrangulating intestinal infarctions associated with Strongylus vulgaris: clinical presentation and treatment outcomes of 30 horses (2008-2016). Equine Vet J. 2018:50:474-80

21. Martinez-Subiela S, Ceron JJ. Effects of hemolysis, lipemia, hyperbilirrubinemia, and anticoagulants in canine C-reactive protein, serum amyloid A, and ceruloplasmin assays. Can Vet J. 2005;46:625-9.

22. Stoneham SJ, Palmer L, Cash R, Rossdale PD. Measurement of serum amyloid $\mathrm{A}$ in the neonatal foal using a latex agglutination immunoturbidometric assay: determination of the normal range, variation with age and response to disease. Equine Vet J. 2001:33:599-603.

23. Vinther AM, Heegaard PM, Skovgaard K, Buhl R, Andreassen SM, Andersen $\mathrm{PH}$. Characterization and differentiation of equine experimental local and early systemic inflammation by expression responses of inflammationrelated genes in peripheral blood leukocytes. BMC Vet Res. 2016:12:83.

24. Jacobsen S, Jensen JC, Frei S, Jensen AL, Thoefner MB. Use of serum amyloid A and other acute phase reactants to monitor the inflammatory response after castration in horses: a field study. Equine Vet J. 2005:37:552-6.

25. Kjelgaard-Hansen MJ, Jensen AL. Reference intervals. In: Weiss DJ, Wardrop KJ, editors. Schalm's veterinary hematology 6. Ames: Wiley-Blackwell; 2010. p. $1034-8$.

26. Kjelgaard-Hansen $M_{\text {, Jensen } A L}$, Kristensen AT. Internal quality control of a turbidimetric immunoassay for canine serum C-reactive protein based on pooled patient samples. Vet Clin Pathol. 2004;33:139-44.

27. Kjelgaard-Hansen M, Jensen AL. Subjectivity in defining quality specifications for quality control and test validation. Vet Clin Pathol. 2010;39: 134-5.

28. Geffre A, Friedrichs K, Harr K, Concordet D, Trumel C, Braun JP. Reference values: a review Vet Clin Pathol. 2009:38:288-98.

\section{Publisher's Note}

Springer Nature remains neutral with regard to jurisdictional claims in published maps and institutional affiliations.
Ready to submit your research? Choose BMC and benefit from:

- fast, convenient online submission

- thorough peer review by experienced researchers in your field

- rapid publication on acceptance

- support for research data, including large and complex data types

- gold Open Access which fosters wider collaboration and increased citations

- maximum visibility for your research: over $100 \mathrm{M}$ website views per year

At $\mathrm{BMC}$, research is always in progress.

Learn more biomedcentral.com/submissions 